\title{
MECKEL'S DIVERTICULUM SERIES AT UCMS, BHAIRAHAWA, NEPAL
}

\author{
Joshi P.*
}

\section{INTRODUCTION}

Meckel's Diverticulum is the most common congenital malformation of the Gastrointestinal tract. It represent the patent intestinal end of the vitellointestinal duct. It occurs in $2 \%$ of of population in autospy series and usually lie $60 \mathrm{~cm}$ from the Ileocaecal junction. It possesses all the three coats of intestinal wall. It has the same microscopic structure as the adjacent small bowel and it has a separate blood supply from the adjacent small bowel mesentery (the omphalomesenteric artery). ${ }^{1}$ In $20 \%$ of the cases, the mucosa contains heterotopic epithelium, namely gastric, colonic and sometimes pancreatic tissue. Although Meckel's diverticulum occurs with equal frequency in both sexes, symptoms usually resulting from the epithelium contained in the diverticulum predominantly occur in males. ${ }^{2}$

Complications develop in only $4 \%$ of patients with this malformation, with most cases presenting in childhood ${ }^{3}$. Complications of Meckel's diverticulum include hemorrhage, bowel obstruction, inflammation, and perforation. All of these complications can be challenging to diagnose because patients may present with non-specific symptoms, which produce a clinical picture that can mimic other more common gastrointestinal disorders. ${ }^{4}$ Most of the cases are diagnosed intraoperatively. Here, we present a case series of 5 patients in a year 2012 at Universal College of Medical College \& Teaching Hospital, Bhairahawa, Nepal.

\section{CASE SERIES}

There were total 5 patients who were diagnosed as a case of Meckel's diverticulum intraoperatively. Four of the patients were presented clinically as Acute Small Bowel Obstruction and one patient presented with the clinical picture of Acute Appendicitis. The age ranges from 15 to 33 years old with mean age of 21 . All the patient were male. Abdominal pain was the most consistent symptom in all the patient located centrally at periumbilical region initially which became diffused over whole abdomen, associated with vomiting and distention in four patient and shifted to Right Iliac fossa in one patient. The clinical diagnosis of acute small bowel obstruction was made with the clinical finding of distended abdomen and dilated small bowel loop in supine abdominal X-Ray in 4 patient whereas the presence of right iliac fossa pain with Tenderness at same place and presence of rebound tenderness with laboratory finding of leucocytosis points towards acute appendicitis in one patient. Moreover, the preoperative diagnosis of acute appendicitis was supported by the collection noted at Right iliac fossa in ultrasonographic study. There were no significant past medical and surgical history in any patient. All the patient went Surgical exploration with the presumed diagnosis of acute small bowel obstruction or acute appendicitis and the intraoperative finding were noted.

* Assistant Professor, Department of Surgery, Universal College of Medical Sciences \& Teaching Hospital, Bhairahawa, Nepal

\author{
For Correspondence \\ Dr.Pravin Joshi, M.S., \\ Assistant Professor, \\ Department of Surgery, \\ Universal College of Medical Sciences \&Teaching Hospital, \\ Bhairahawa, Nepal \\ E-mail: drpravin_2008@yahoo.com
}


In the small bowel obstruction group, the small bowels were noted to be dilated. The position of meckel's diverticulum varies from 15 to $60 \mathrm{~cm}$ from Ileocaecal junction. All the diverticulum found has wide neck and the length varied from 5 $\mathrm{cm}$ to $10 \mathrm{~cm}$. The diverticulum was found to be erythematous and edematous with fibrinous plaque over it and adjacent small bowel loop. The adjacent bowel loop was intimately adhered to meckel's diverticulum in 3 patients while in 1 patient, the meckel's diverticulum was noted to be rotated around the distal ileum, wrapping it completely and tip adhered near to Ileocaecal junction causing external compression of the distal ileum causing intestinal obstruction. All the patient underwent diverticulectomy. Postoperatively, the recovery was unremarkable.In a patient presented as acute appendicitis, the meckel's diverticulum was found $16 \mathrm{~cm}$ proximal to Ileocaecal junction and the diverticulum was found to be intensly erythematous with beefy red colour that had subsequently involved 8 cam distal ileum as well. The appendix was found normal. The patient was subjected to resection of the involved segment with end to end anastomosis of the ileum. No adverse event occurred in postoperative period.

\section{DISCUSSION}

Meckel's diverticulum was originally described by Fabricius Hildanus in 1598. However, it is named after Johann Friedrich Meckel, who established its embryonic origin in 1809. Although Meckel's diverticulum is a common congenital anomaly of the gastrointestinal tract, it is often difficult to diagnose and most are diagnosed post complication of diverticulum during surgery for other presumed cause.

In a large series of 1476 cases of Meckel's diverticulum found during the operation, from a single institute over 52 yrs, PARK et al. have noted that $84 \%$ were asymptomatic and $16 \%$ were symptomatic. ${ }^{5}$ The mean age of patients with a symptomatic Meckel's diverticulum was 31. The frequency of symptomatic Meckel's diverticulum decreased with age. The male- female ratio was approximately $3: 1.29 \%$ of all Meckel's diverticula contained ectopic or abnormal tissue.

The lifetime risk of complications in patients with a Meckel's diverticulum is estimated to be $4 \%{ }^{6}$ In adult patients, intestinal obstruction is the most common complication $(40 \%)$ and in children, gastrointestinal haemorrhage. A Meckel's diverticulum may result in small bowel obstruction by a variety of mechanisms: by entangling a loop of small bowel around a fibrous cord or within a mesodiverticular band, intussusception, volvulus, incarceration within a hernia sac (Littre's hernia), chronic Meckel's diverticulitis, foreign body, or neoplasm . Stasis within the blind sac of meckel diverticulum leads to inflammation causing meckel diverticulitis and due to its proximity to appendix, it mimics acute appendicitis. ${ }^{6}$
Our case series are consistent with the reported literature of meckel's diverticulum and its complications. The intraoperative diagnoses made in all cases suggest that we lack certain logistic resource in preoperative identification of the disease process. CT-Scan in not available widely and unaffordable by the rural people, mostly presenting to our setup and there is no availability of nuclear imaging that has high sensitivity and specificity. Moreover, even when available, delay in exploration and definite treatment cannot be avoided, leading to difficult convalescent period. Hence, as of now, clinical suspicion is the only way out in diagnosis of complicated meckel's diverticulum.

\section{CONCLUSION}

This series therefore highlights the importance of considering a Meckel's diverticulum as a cause of small bowel obstruction in individuals from all age groups and especially in a person with no previous abdominal pathology or surgery. Similarly, in suspected acute appendicitis, if the appendix is found normal, search for meckel diverticulum is required. Since no adverse events were noted in postoperative and convalescent period, definite diagnosis preoperative though preferred, should not be mandatary and exploration should be carried out without delay for expensive and unavailable investigations.

\section{REFERENCES}

1. Steele RJC. Disorders of the small intestine and vermiform appendix. In Cusheiri A, Steele RJC, Moosa AR. Essential Surgical Practice. 4th Edition. London: Arnold, 2002. p 567.

2. Jones $O$, Mortenson, JMC Neil. The small and large intestines. Russell RCG, Williams N S, Bulstrode CJK. Bailey \& Love's Short Practice of Surgery. 24th Edition. London: Arnold, 2004. p 1159.

3. Turgeon DK, Barnett JL: Meckel's diverticulum. Am J Gastroenterol 1990, 85:777-781.

4. Yahchouchy EK, Marano AF, Etienne JC, Fingerhut AL: Meckel's diverticulum. J Am Coll Surg 2001, 192:658-662.

5. Park JJ, Wolff BG, Tollefson MK, Walsh EE, Larson DR. Meckel diverticulum: the Mayo Clinic experience with 1476 patients (1950-2002). Ann Surg, 2005, 241 (3) : 52933

6. Prall RT, Bannon MP, Bharucha AE. Meckel's diverticulum causing intestinal obstruction. Am J Gastroenterol, 2001, 96(12): 3426-7. 